\title{
QUALIDADE NUTRICIONAL E SUSTENTABILIDADE AMBIENTAL EM CARDÁPIO COM DIFERENTES FONTES PROTEICAS NA ALIMENTAÇÃO ESCOLAR DO MUNICÍPIO DE NITERÓI (RJ)
}

\author{
Ana Cristina Cordeiro ${ }^{1}$ \\ Patricia Dias ${ }^{2}$ \\ Daniele Ferreira ${ }^{3}$ \\ Roseane Barbosa ${ }^{4}$ \\ Daniele Soares 5
}

Resumo: $O$ estudo analisou indicadores de sustentabilidade ambiental e qualidade nutricional de cardápios do Programa Nacional de Alimentação Escolar do ensino fundamental do município de Niterói, no período de setembro a dezembro de 2019. Calculou-se a pegada de carbono, pegada hídrica e pegada ecológica dos cardápios com e sem proteína de origem animal. Assim como a energia, os macros e micronutrientes e o Índice de Qualidade da Coordenação de Segurança Alimentar e Nutricional. O cardápio sem carne ou à base de ovo foram aqueles considerados mais sustentáveis, com impacto ambiental de 3 a 5,5 vezes menor que os demais cardápios e estavam nutricionalmente adequados. O planejamento dos cardápios escolares pode ser uma ferramenta na redução dos impactos ambientais.

Palavras-chave: Sustentabilidade; Composição Nutricional; Conservação dos Recursos Naturais; Alimentação Escolar; Educação Ambiental.

\footnotetext{
${ }^{1}$ Universidade Federal Fluminense. E-mail: freitas.nutri@gmail.com. Link para o Lattes: http://lattes.cnpq.br/1627552566370236

2 Universidade Federal Fluminense. E-mail: diaspc2@gmail.com. Link para o Lattes: http://lattes.cnpq.br/2032672242741923

3 Universidade Federal Fluminense. E-mail: daniele ferreira@id.uff.br. Link para o Lattes: http://lattes.cnpq.br/6222513276436258

4 Universidade Federal Fluminense.E-mail: roseanesampaio@id.uff.br. Link para o Lattes: http://lattes.cnpq.br/4211691428243654

5 Universidade Federal Fluminense. E-mail: danielebastos@id.uff.br. Link para o Lattes: http://lattes.cnpq.br/1163585343443325
} 
Abstract: The study analyzed indicators of environmental sustainability and nutritional quality of menus of the National School Feeding Program of elementary school of Niterói city (RJ, Brazil), from September to December 2019. The carbon footprint, water footprint and ecological footprint of the menus with and without animal protein were calculated. As well as energy, macros and micronutrients and the Quality Index of the Food and Nutrition Security Coordination. The meatless or egg-based menus were those considered more sustainable, with an environmental impact of 3 to 5.5 times less than the other menus and were nutritionally adequate. The planning of school menus can be a tool in reducing environmental impacts.

Keywords: Sustainability; Nutritional Composition; Conservation of Natural Resources; School Feeding; Environmental Education.

\section{Introdução}

Os avanços tecnológicos permitiram rápida expansão da agropecuária moderna, ampliação da produção e mudanças no consumo dos alimentos, com resultados negativos sobre o meio ambiente e sobre a saúde das pessoas. Em todo o mundo identificam-se mudanças no padrão alimentar relacionadas aos sistemas produtivos que incidem sobre a quantidade, qualidade, processos empregados e disponibilidade dos alimentos à população (HIGH LEVEL PANEL OF EXPERTS, 2017).

A reconfiguração dos sistemas produtivos e das práticas alimentares podem reduzir o uso de recursos naturais e, consequentemente, minimizar os impactos ambientais quando são implementadas em larga escala (RANGANATHAN, 2016). Tais mudanças transformam o modo de pensar a alimentação e sua relação com o meio ambiente. Alimentos considerados saudáveis precisam estar relacionados a um sistema alimentar ambientalmente sustentável (MARTINELLI; CAVALLI, 2019).

A sustentabilidade ambiental ganhou certa centralidade no debate internacional, integrando a Agenda 2030 para o Desenvolvimento Sustentável, na qual recebe destaque a importância de proteger o planeta da degradação, incluindo o consumo e a produção sustentáveis, a gestão sustentável dos seus recursos naturais e medidas urgentes para combater a mudança do clima (ORGANIZAÇÃO DAS NAÇÕES UNIDAS, 2015).

Segundo a Food and Agriculture Organization (2010), dietas sustentáveis são aquelas com baixo impacto ambiental que contribuem para a segurança alimentar e nutricional e para uma vida saudável no presente e nas gerações futuras. A adoção de práticas alimentares mais sustentáveis pode ser promovida por meio de diferentes estratégias, desde medidas individuais a desenhos de políticas públicas que incluam como objetivo ou princípio a preservação ambiental.

O Programa Nacional de Alimentação Escolar (PNAE) representa um dos principais programas de Segurança Alimentar e Nutricional (SAN). 
Destinado aos escolares da rede pública de ensino, tem por objetivo contribuir para o crescimento e o desenvolvimento biopsicossocial, a aprendizagem, o rendimento escolar e a formação de práticas alimentares saudáveis dos alunos, por meio de ações de educação alimentar e nutricional e da oferta de refeições que cubram as suas necessidades nutricionais durante o período letivo (BRASIL, 2020). Em suas diretrizes, o PNAE apresenta, em seu marco legal, o direito à alimentação escolar saudável e adequada respeitando as diferenças biológicas entre idades e condições de saúde dos alunos, compreendendo o uso de alimentos variados, seguros, que respeitem a cultura, as tradições e os hábitos alimentares saudáveis. Ademais, o Programa também apoia 0 desenvolvimento sustentável incentivando a compra de alimentos da agricultura familiar com a valorização das culturas agroecológicas e orgânicas, especialmente oriundas de comunidades tradicionais (BRASIL, 2009).

No entanto, são escassos os estudos que analisam a composição dos cardápios escolares quanto ao seu impacto ambiental.

$\mathrm{O}$ uso de indicadores ambientais, tais como pegada hídrica, pegada de carbono e pegada ecológica na análise de cardápios podem auxiliar na detecção dos pontos críticos e na definição de parâmetros objetivos para a escolha de alimentos ou na adoção de práticas favoráveis ao meio ambiente. Tais pegadas analisam o gasto de água, o potencial de emissão de gases de efeito estufa e o impacto das atividades humanas na capacidade regenerativa da terra em toda a cadeia produtiva do alimento (GARZILLO et al., 2019).

Assim, este estudo tem como objetivo analisar os cardápios da alimentação escolar do município de Niterói quanto a critérios de sustentabilidade ambiental, composição nutricional e Índice de Qualidade da Coordenação de Segurança Alimentar e Nutricional (IQ COSAN).

\section{Métodos}

O município em análise introduziu, em seu cardápio escolar oficial, o dia da Alimentação Consciente (AC), contendo apenas alimentos de origem vegetal uma vez na semana para o ensino em período parcial. Tendo em vista as alterações efetuadas no cardápio da alimentação escolar, realizou-se uma análise da composição nutricional e qualidade nutricional associadas ao uso de indicadores de sustentabilidade. A garantia de uma alimentação adequada quanto ao aporte nutricional no contexto do PNAE recebe destaque considerando o perfil socioeconômico do público atendido pelas escolas públicas.

Trata-se de um estudo observacional, transversal e de análise quantitativa. Foram analisados os cardápios oficiais das quatro semanas da alimentação escolar para o ensino fundamental do turno parcial do município do Niterói (RJ) referentes ao período de setembro a dezembro de 2019. Os cardápios escolares são de domínio público, e foi disponibilizado pela equipe de nutricionistas do Departamento de Alimentação Escolar do município em estudo.

Revbea, São Paulo, V. 16, № 3: 330-346, 2021. 
Optou-se por escolher o cardápio do ensino regular, dos anos iniciais e finais do ensino fundamental e turno parcial devido ao número de alunos matriculados neste segmento, 18.881 , que corresponde a $73 \%$ do total de alunos matriculados na rede de ensino do município em estudo. Além disso, o número de alunos matriculados no turno parcial é de 18.149, que representa $96 \%$ do total de alunos matriculados no ensino fundamental segundo o Censo Escolar (2019).

Os cardápios oficiais são elaborados por nutricionistas da entidade executora municipal do PNAE e padronizados para a rede de ensino de Niterói, porém existem diferenciações quanto à modalidade de ensino (integral ou parcial). O cardápio para o turno parcial apresenta, no dia da $A C$, alimentos apenas de origem vegetal, já o cardápio para o turno integral contém a presença do grupo do leite no dia da AC.

As quantidades dos alimentos oferecidos foram obtidas através do registro de porcionamento anexado ao cardápio oficial da alimentação escolar elaborado pela equipe técnica de nutricionistas. No momento da realização da pesquisa, não constava a presença de fichas técnicas. Sendo assim, optou-se por transformar as medidas caseiras em gramas com o uso da Tabela para Avaliação de Consumo Alimentar em Medidas Caseiras (PINHEIRO et al., 2008).

Os indicadores de sustentabilidade ambiental calculados foram: pegada de carbono, pegada hídrica e pegada ecológica das 4 semanas que compõem o cardápio da alimentação escolar. Cada dia da semana é composto por duas refeições: desjejum e almoço para o turno da manhã e almoço e lanche para o turno da tarde.

Para este cálculo utilizou-se a referência de Pegadas dos Alimentos e das Preparações Culinárias Consumidos no Brasil da Faculdade de Saúde Pública da Universidade de São Paulo (GARZILLO et al., 2019).

Tendo em vista que o dia da $A C$ é realizado apenas às quartas-feiras, foram comparadas as medianas das pegadas de carbono, pegada hídrica e pegada ecológica entre os dias da semana (segunda-feira, terça-feira, quintafeira e sexta-feira) e a quarta-feira. Para analisar a redução do impacto ambiental dos cardápios, calculou-se o percentual de redução nos valores de cada indicador de sustentabilidade, com base na média (4 dias) do cardápio do dia da AC comparado a média dos demais cardápios (16 dias).

Com auxílio da Tabela Brasileira de Composição de Alimentos da Universidade Estadual de Campinas (2011), foram calculados macronutrientes (carboidratos, proteínas, lipídios) e micronutrientes (cálcio, ferro, zinco, magnésio, vitamina $A$ e vitamina $C$ ) do cardápio do dia da $A C$, cardápio cujo prato principal era carne bovina, frango e ovo. Foram comparados os valores de medianas de energia e nutrientes de cada semana com os valores de referência do PNAE (Resolução ํo 26 de 17 de junho de 2013). 
O cálculo do índice da qualidade da alimentação escolar foi realizado utilizando-se a ferramenta IQ COSAN desenvolvida pelo Fundo Nacional de Desenvolvimento da Educação (FNDE) no programa Excel. Na avaliação do cardápio, é somada a pontuação de cada semana e calculadas as médias semanais. O escore do IQ COSAN varia entre 0 e 95 pontos e os cardápios são classificados em: Inadequado ( 0 a 45,9 pontos), Precisa de melhoras (46 a 75,9 pontos) e Adequado (76 a 95 pontos) (BRASIL, 2018).

Este índice avalia quatro parâmetros: a) presença de seis grupos de alimentos (1. cereais e tubérculos; 2 . feijões; 3 . legumes e verduras; 4 . frutas in natura; 5. leites e derivados; 6 . carnes e ovos); b) Presença de alimentos regionais e da sociobiodiversidade; c) Diversidade semanal das refeições ofertadas; d) Ausência de alimentos classificados como restritos, proibidos e alimentos ou preparações doces.

Considerando a distribuição não paramétrica das variáveis, a análise estatística dos indicadores de sustentabilidade dos cardápios (pegada hídrica, de carbono e ecológica) foi realizada por meio do teste de Krulkall-Wallis para identificar diferenças entre as medianas dos cardápios de cada dia da semana. Ao identificar valores de $p<0,05$, foi realizado o teste de Mann-Whitney para comparar as medianas de cada dia da semana (cardápios com proteína animal) com a mediana da quarta-feira (cardápio sem proteína animal). Para a análise da diferença mediana da composição nutricional (energia, carboidratos, proteínas, lipídeos, fibra alimentar, vitamina A, vitamina C, cálcio, ferro, magnésio e zinco) dos cardápios com e sem proteína animal em relação aos valores recomendados pelo PNAE na Resolução no 26 de 17 de junho de 2013 foi realizada a análise estatística com o cálculo do teste de Wilcoxon de amostra única considerando o nível de significância em 5\%. Todas as análises foram realizadas utilizando o software JASP 0.13.1.0.

Este trabalho foi aprovado no Comitê de Ética em Pesquisa da Universidade Federal Fluminense sob 0 parecer $n^{\circ}$ CAAE:98417718.5.0000.5243.

\section{Resultados}

De acordo com a análise dos indicadores de sustentabilidade, há um grau de variação elevado nos valores relacionados à pegada de carbono, pegada hídrica e pegada ecológica nas terças-feiras e sextas-feiras, pois no cardápio ocorre variação quanto ao prato principal no almoço, composto por frango ou carne bovina (Figura 1; Figura 2; Figura 3).

Os cardápios referentes à segunda-feira têm o ovo como prato principal no almoço. O valor extremo (outlier) observado nos cardápios de segunda-feira é resultado da presença do atum em conserva em uma semana. O valor outlier observado na quinta-feira é devido à presença de fígado bovino em uma semana, nas demais há a presença de frango como prato principal. 


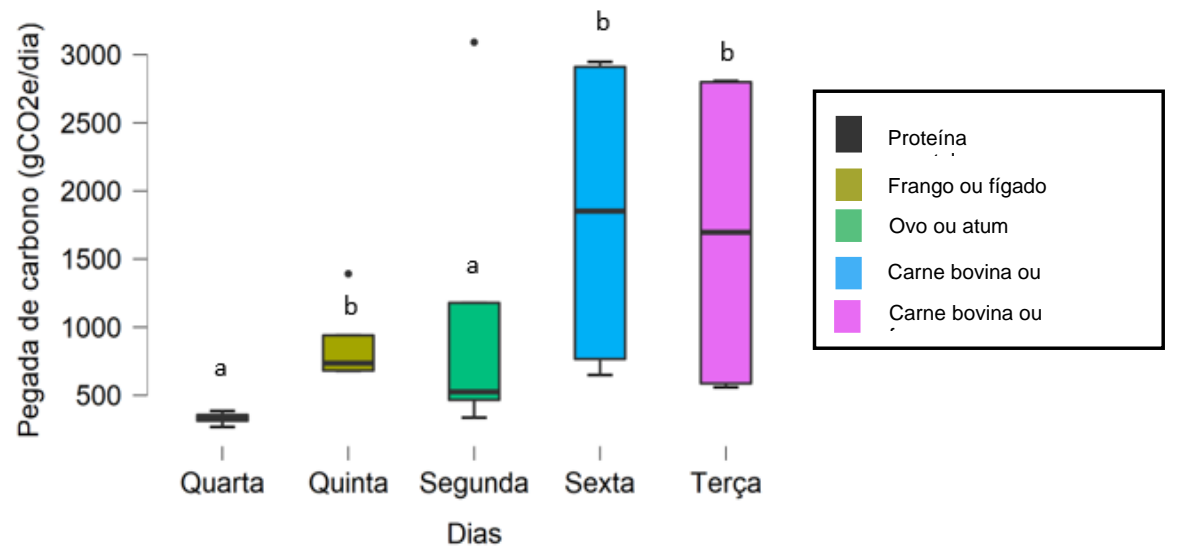

As letras diferentes indicam valores significativamente diferentes $(p$ $<0,05)$ em comparação com o dia da Alimentação Consciente (Quarta).

Figura 1: Mediana da pegada de carbono dos cardápios do ensino fundamental (turno parcial) para o ano de 2019, município de Niterói.

Fonte: autoria própria.

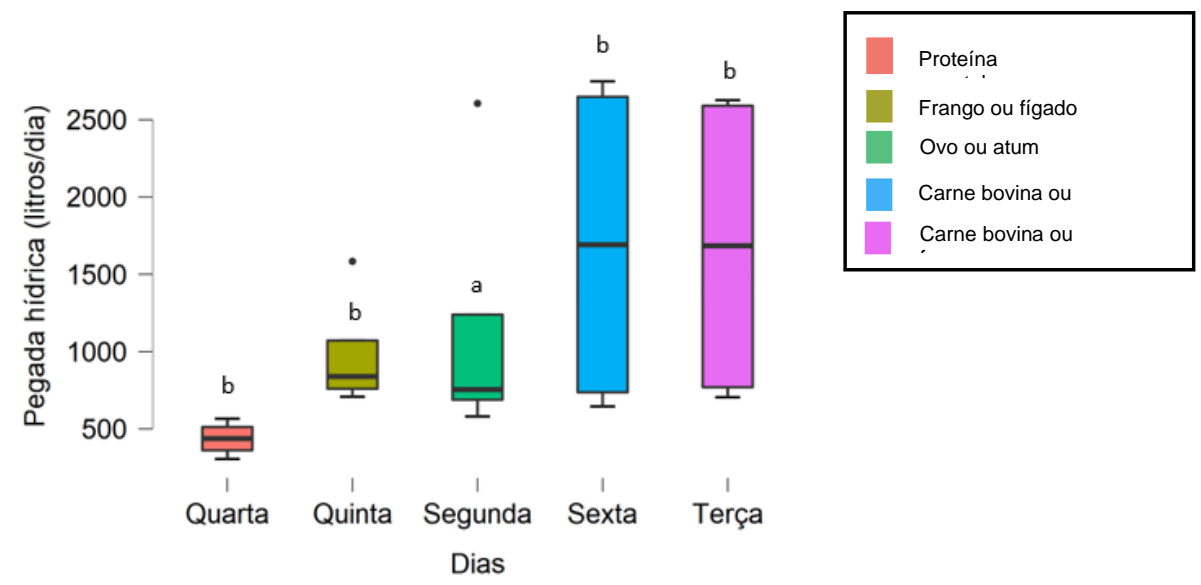

As letras diferentes indicam valores significativamente diferentes $(p<0,05)$ em comparação com o dia da Alimentação Consciente (Quarta).

Figura 2: Mediana da pegada hídrica dos cardápios do ensino fundamental (turno parcial) para o ano de 2019, município de Niterói.

Fonte: autoria própria. 


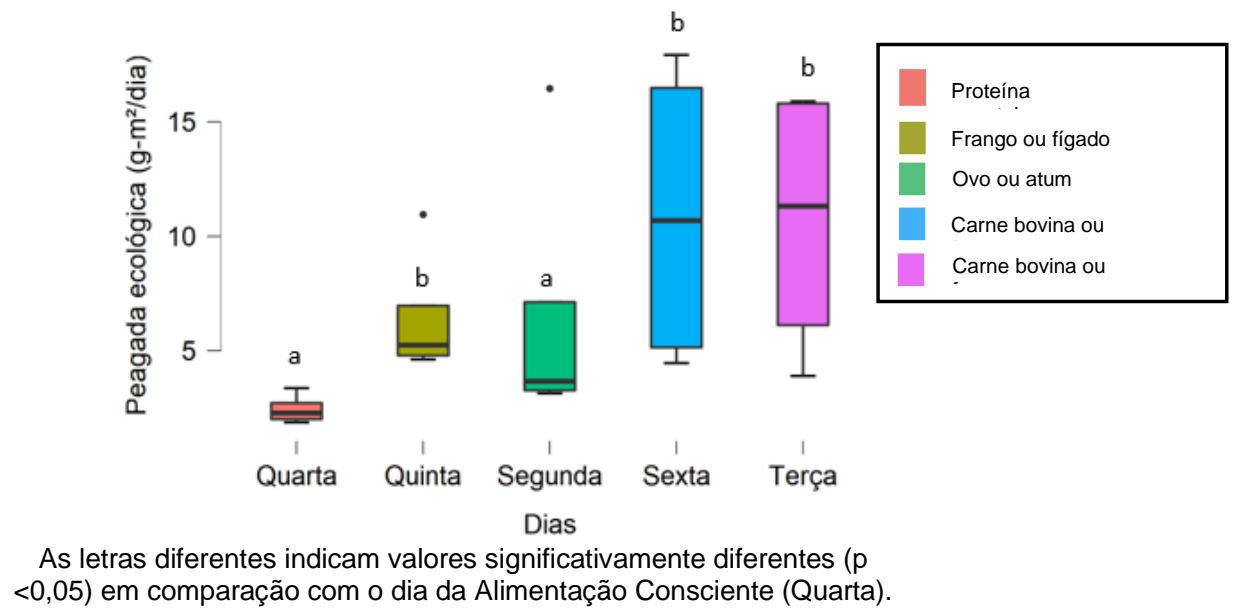

Figura 3: Mediana da pegada ecológica dos cardápios do ensino fundamental (turno parcial) para o ano de 2019, município de Niterói.

Fonte: autoria própria.

Observa-se uma diferença significativa quando é comparado o cardápio do dia da AC (quarta-feira) aos demais dias da semana para a pegada de carbono, pegada hídrica e pegada ecológica (Figura 1; Figura 2; Figura 3), exceto para o cardápio da segunda-feira, possivelmente pela presença do ovo como prato principal (Figura 1; Figura 3).

Em média, o dia da AC reduziu a pegada de carbono em $76 \%$, a pegada hídrica em $68,5 \%$ e a pegada ecológica em $71,9 \%$ para o dia da quarta-feira. Estes resultados apontam para uma estimativa de que cada aluno, em média, reduziu a emissão 4.194,2g de gases de efeito estufa, deixou de usar $3.789,4$ litros de água e reduziu o impacto na capacidade regenerativa da terra em $25 \mathrm{~m}^{2}$ em cada quarta-feira.

De acordo com a análise da composição nutricional, observa-se que não houve diferença significativa para energia, assim como para nenhum nutriente quando comparada a mediana semanal com a referência por faixa etária (Tabela 1; Tabela 2).

Os valores das medianas de energia e nutrientes dos cardápios semanais encontram-se iguais nas Tabelas 1 e 2 porque não há diferença entre os porcionamentos nas duas faixas etárias em análise. 
Tabela 1: Comparação entre os valores de referência de energia e nutrientes recomendados pelo Programa Nacional de Alimentação Escolar (PNAE) para a faixa etária de 6 a 10 anos e a mediana da Semana A, Semana B, Semana C e Semana D dos cardápios do turno parcial (RJ).

\begin{tabular}{|c|c|c|c|c|c|c|c|c|c|}
\hline $\begin{array}{l}\text { Energia e } \\
\text { nutrientes }\end{array}$ & $\frac{\text { PNAE }}{\text { (6 a } 10 \text { anos) }}$ & $\int_{A}^{\text {Semana }}$ & Valor $p$ & $\underset{B}{S e m a n a}$ & Valor $p$ & $\underset{C}{S e m a n a}$ & Valor $p$ & $\underset{D}{S e m a n a}$ & Valor $p$ \\
\hline Energia (Kcal) & 450,0 & 747,8 & 0,063 & 743,5 & 0,058 & 759,4 & 0,063 & 761,5 & 0,063 \\
\hline Carboidratos (g) & 73,1 & 114,2 & 0,063 & 107,7 & 0,063 & 123,1 & 0,063 & 116,7 & 0,063 \\
\hline Proteína (g) & 14,0 & 31,1 & 0,063 & 37,2 & 0,063 & 33,7 & 0,063 & 38,0 & 0,063 \\
\hline Lipídeos (g) & 11,3 & 17,5 & 0,313 & 17,4 & 0,313 & 20,3 & 0,125 & 20,4 & 0,125 \\
\hline $\begin{array}{l}\text { Fibra Alimentar } \\
\text { (g) }\end{array}$ & 8,0 & 10,1 & 0,100 & 10,1 & 0,058 & 10,8 & 0,063 & 10,4 & 0,063 \\
\hline Vitamina A (mcg) & 150,0 & 220,6 & 0,063 & 281,5 & 0,125 & 222,6 & 0,313 & 255,6 & 0,063 \\
\hline Vitamina C (mg) & 11,0 & 21,6 & 0,125 & 25,7 & 0,313 & 24,3 & 0,313 & 23,7 & 0,125 \\
\hline Cálcio (mg) & 315,0 & 227,5 & 0,313 & 342,5 & 0,625 & 344,4 & 0,625 & 346,1 & 0,625 \\
\hline Ferro (mg) & 2,7 & 5,2 & 0,063 & 4,1 & 0,058 & 5,5 & 0,063 & 4,5 & 0,063 \\
\hline Magnésio (mg) & 56,0 & 128,1 & 0,063 & 141,6 & 0,063 & 138,4 & 0,063 & 138,6 & 0,063 \\
\hline Zinco (mg) & 2,0 & 4,6 & 0,125 & 3,4 & 0,058 & 5,3 & 0,063 & 4,8 & 0,063 \\
\hline
\end{tabular}

Fonte: autoria própria.

Vale ressaltar que os valores de energia, macronutrientes e micronutrientes apesar de não existirem diferenças significativas na análise estatística quando realizada a média semanal, conforme a recomendação da Resolução no 26 de 17 de junho de 2013, o mineral cálcio apresentou valores abaixo da recomendação nas semanas $A, B$ e $C$ na faixa etária de 6 a 10 anos e nas semanas $A, B, C$ e D na faixa etária de 11 a 15 anos. 
Tabela 2. Comparação entre os valores de referência de energia e nutrientes recomendados pelo Programa Nacional de Alimentação Escolar (PNAE) para a faixa etária de 11 a 15 anos e a mediana da Semana A, Semana B, Semana C e Semana D dos cardápios do turno parcial (RJ).

\begin{tabular}{|c|c|c|c|c|c|c|c|c|c|}
\hline $\begin{array}{l}\text { Energia e } \\
\text { nutrientes }\end{array}$ & $\begin{array}{c}\text { PNAE } \\
\text { (11 a } 15 \text { anos) }\end{array}$ & $\underset{A}{\text { Semana }}$ & Valor $p$ & $\underset{\text { B }}{\text { Semana }}$ & Valor $p$ & $\underset{\text { C }}{\text { Semana }}$ & Valor $p$ & $\underset{D}{\text { Semana }}$ & Valor $p$ \\
\hline Energia (Kcal) & 650,0 & 747,8 & 0,063 & 743,5 & 0,058 & 759,4 & 0,063 & 761,5 & 0,063 \\
\hline Carboidratos (g) & 105,6 & 114,2 & 0,063 & 107,7 & 0,063 & 123,1 & 0,063 & 116,7 & 0,063 \\
\hline Proteína (g) & 20,3 & 31,1 & 0,063 & 37,2 & 0,063 & 33,7 & 0,063 & 38,0 & 0,063 \\
\hline Lipídeos (g) & 16,3 & 17,5 & 0,313 & 17,4 & 0,313 & 20,3 & 0,125 & 20,4 & 0,125 \\
\hline $\begin{array}{l}\text { Fibra Alimentar } \\
\text { (g) }\end{array}$ & 9,0 & 10,1 & 0,100 & 10,1 & 0,058 & 10,8 & 0,063 & 10,4 & 0,063 \\
\hline Vitamina A (mcg) & 210,0 & 220,6 & 0,063 & 281,5 & 0,125 & 222,6 & 0,313 & 255,6 & 0,063 \\
\hline Vitamina C (mg) & 18,0 & 21,6 & 0,125 & 25,7 & 0,313 & 24,3 & 0,313 & 23,7 & 0,125 \\
\hline Cálcio (mg) & 390,0 & 227,5 & 0,313 & 342,5 & 0,625 & 344,4 & 0,625 & 346,1 & 0,625 \\
\hline Ferro $(\mathrm{mg})$ & 3,3 & 5,2 & 0,063 & 4,1 & 0,058 & 5,5 & 0,063 & 4,5 & 0,063 \\
\hline Magnésio (mg) & 95,0 & 128,1 & 0,063 & 141,6 & 0,063 & 138,4 & 0,063 & 138,6 & 0,063 \\
\hline Zinco (mg) & 2,7 & 4,6 & 0,125 & 3,4 & 0,058 & 5,3 & 0,063 & 4,8 & 0,063 \\
\hline
\end{tabular}

Fonte: autoria própria.

Pela análise do IQ COSAN identificou-se que os grupos das carnes e ovos e o do grupo do leite e derivados estão ausentes no cardápio parcial no dia da AC, recebendo a pontuação de 0 (zero) para este dia da semana. No entanto, os resultados gerais indicaram que todos os cardápios estavam adequados com pontuação acima de 76 pontos. Tal classificação é resultado da presença dos demais grupos alimentares em todos os dias da semana, ausência de alimentos restritos, controle de alimentos doces, presença de alimentos regionais, diversidade do cardápio e ausência de alimentos proibidos. 


\section{Discussão}

O cardápio sem proteína de origem animal (quarta-feira) apresentou menores valores de pegada de carbono, pegada hídrica e pegada ecológica do que os cardápios com alimentos de origem animal, mostrando seu potencial na promoção da sustentabilidade ambiental por meio da alimentação escolar.

A pegada hídrica é um indicador do uso de água considerando não apenas o uso direto da água de um consumidor ou produtor, mas também no uso indireto. O seu cálculo envolve estes três componentes principais: água de superfície ou subterrânea (água azul); água de chuva (água verde) e água necessária para assimilar a carga de poluição do sistema de produção e consumo (água cinza) (GARZILLO et al., 2019).

A pegada de carbono mede a emissão de gases de efeito estufa emitidos direta e indiretamente por uma atividade ou o total da emissão ao longo do ciclo de vida de um produto (GARZILLO et al., 2019).

A pegada ecológica revela quanto a humanidade demanda da capacidade regenerativa da terra, neste caso, na produção e elaboração de um produto. Segundo Garzillo et al. (2019) para o seu cálculo são utilizadas seis variáveis: terras cultivadas (alimentos de origem vegetal e fibras para tecelagem ou papel); terras cultivadas e pastagens (alimentos de origem animal); áreas de pesca (alimentos oriundos da pesca); áreas de sequestro de carbono (absorção das emissões de carbono de origem fóssil); área construída (provisionamento de espaço físico para abrigo e infraestrutura).

Já é conhecido na literatura que dietas veganas causam menor impacto ao meio ambiente do que dietas que incluem alimentos de origem animal. Em um estudo realizado com 153 adultos italianos (51 onívoros, 51 ovo-lacto-vegetarianos e 51 veganos) calculou-se as pegadas hídricas, pegadas de carbono e pegadas ecológicas da ingestão alimentar através do registro alimentar de 7 dias. A dieta onívora gerou pegada de carbono, de água e pegada ecológica piores do que as demais dietas, porém não foram encontradas diferenças significativas nos impactos ambientais entre os ovolacto-vegetarianos e veganos (ROSI et al., 2017).

Em um estudo realizado em uma Instituição Universitária na região Sul do Brasil apresentou a pegada de carbono e a pegada ecológica da oferta média do cardápio do restaurante universitário, e constatou-se que os alimentos de origem animal representaram $52,7 \%$ dos alimentos oferecidos no cardápio. Estes contribuíram duas vezes mais para a emissão de gases de efeito estufa quando comparado aos alimentos de origem vegetal. A pegada ecológica dos alimentos de origem animal foi maior que a dos alimentos de origem vegetal. Os autores ressaltam a importância da pegada de carbono e pegada ecológica como ferramentas transversais tornando-se peças fundamentais na gestão ambiental do campus (LIED et al., 2019).

Em um estudo suíço apresentou a pegada de carbono, pegada hídrica e pegada ecológica de nove cenários alimentares diferentes: dieta suíça 
saudável, dieta global saudável, vegetariana, vegana, pescetariana (vegetariana que permite o consumo de peixes e frutos do mar), flexitariana (vegetariana e ocasionalmente o consumo de carne), dieta rica em proteínas, dieta rica em carne e uma dieta de imposto sobre gases de efeito de estufa. Esta última é uma alternativa de dieta como consequência da cobrança de um imposto sobre gases de efeito estufa sobre produtos alimentícios. A dieta suíça saudável, seguindo as diretrizes da sociedade suíça de nutrição, foi a mais sustentável por resultar em $36 \%$ de redução nos valores das pegadas (CHEN et al., 2019).

Os resultados deste estudo apontam que mudar para uma dieta saudável, de acordo com as diretrizes da sociedade suíça de nutrição, além de ser adequada para a saúde humana é também apropriado para o meio ambiente. Neste sentido a elaboração de diretrizes nacionais e políticas públicas para a alimentação saudável recebe importância também na contribuição para a redução do impacto ambiental.

A Society for Nutrition Education and Behavior (SNEB) enfatiza que a sustentabilidade ambiental deve integrar as orientações dietéticas no guia alimentar nacional. As dietas e práticas agrícolas atuais promovem impactos ambientais que ameaçam a segurança alimentar em longo prazo. Considerando estes impactos em uma projeção de produção de alimentos para uma população crescente, a SNEB enfatiza a necessidade de mudanças no sistema alimentar atual (ROSE et al., 2019).

O Guia Alimentar para a População Brasileira (2014) traz a temática da sustentabilidade ambiental nas escolhas alimentares considerando as formas pelas quais os alimentos são produzidos e distribuídos, privilegiando aqueles cujo sistema de produção e distribuição seja socialmente e ambientalmente sustentável. Destaca que os alimentos in natura ou minimamente processados, os alimentos orgânicos e de base agroecológica como promotores de uma alimentação nutricionalmente balanceada, saborosa, culturalmente apropriada e ambientalmente sustentável. Nesse sentido, cabe destacar a presença de alimentos enlatados no cardápio da alimentação escolar no município em estudo, como o atum, que é classificado como processado. Tratando-se de um município da região litorânea, outras opções proteicas a base de pescado poderia contribuir para reforçar o caráter sustentável do cardápio, como por exemplo as que previlegiam a aquicultura com prática sustentável.

O PNAE ao longo dos anos vem se adaptando às recomendações do Guia Alimentar para a População Brasileira ao priorizar a compra de alimentos in natura ou minimamente processados, ao garantir que $30 \%$ dos recursos sejam utilizados na compra da Agricultura Familiar, ao incentivar a compra de alimentos orgânicos e de base agroecológica para a alimentação escolar (BRASIL, 2020).

A adoção de cardápios sem alimentos de origem animal na alimentação escolar é polêmica e, em alguns municípios, alvo de ações judiciais pela economicidade nos gastos públicos. Nesses casos, os cardápios 
podem ser deficientes em nutrientes, o que pode prejudicar a saúde dos escolares. Segundo a Lei 11.947 de 2009, o PNAE deve oferecer refeições que cubram as necessidades nutricionais dos alunos durante o período letivo, e este estudo mostrou que é possível inserir cardápios sem alimentos de origem animal em um dia na semana, sem comprometer as necessidades nutricionais dos estudantes. Assim, a alimentação escolar pode ser saudável e sustentável.

A qualidade nutricional relacionada aos critérios qualitativos, analisada pelo IQ COSAN, mostrou que o cardápio para o ensino parcial, apesar de em um dia da semana não ter dois grupos alimentares (carne e ovos, e leite e derivados), não interferiu negativamente na qualidade semanal e mensal do cardápio, sendo classificado como adequado.

Estes dados reforçam que um cardápio escolar composto por uma alimentação diversificada, com alimentos in natura ou minimamente processados, com a presença dos diversos grupos alimentares, atendendo a questões regionais e com a presença de alimentos da sociobiodiversidade contribui para uma melhor qualidade alimentar.

Um estudo realizado na alimentação escolar de três escolas públicas de Estocolmo, Suécia, teve como objetivo aplicar a programação de otimização linear para desenvolver um cardápio de almoço de quatro semanas com redução de gases de efeito estufa, nutricionalmente adequado e acessível para alunos de 10 a 12 anos. Como resultado, encontraram a redução de $32 \%$ de carne, $13 \%$ de laticínios, $13 \%$ de frutos do mar, $54 \%$ de frutas e berries, $26 \%$ de temperos e molhos e aumento de $7 \%$ de vegetais e raízes e $5 \%$ de gorduras e óleos (EUSTACHIO et al., 2020).

Estas alterações resultaram na redução média de 40,2\% na emissão de gases do efeito estufa. Os autores destacam que a adequação nutricional foi levemente afetada negativamente para energia, ferro, selênio e zinco. É importante destacar que na alimentação escolar já havia a presença da alimentação vegetariana uma vez na semana e, após a otimização, foram acrescentados mais 2 dias no mês com alimentação vegetariana, resultado em 6 refeições no mês (EUSTACHIO et al., 2020).

Estes resultados corroboram com o presente estudo no qual o cardápio escolar, ao introduzir o dia da $\mathrm{AC}$, projetou uma redução média de $76 \%$ na emissão de gases de efeito estufa na quarta-feira.

Em relação à composição nutricional, observou-se que não há diferença entre os cardápios por faixa etária, o que pode ter contribuído para a menor oferta do mineral cálcio na faixa etária de 11 a 15 anos. Neste sentido, sugere-se a diferenciação do porcionamento quanto às faixas etárias, assim como é recomendado pelo PNAE, uma vez que alunos de diferentes faixas etárias têm necessidades nutricionais específicas e se faz necessário o atendimento dos valores mínimos para garantir a alimentação nutricionalmente adequada.

As decisões em torno do planejamento do cardápio mais sustentável 
possuem relação direta com o tipo de sistema produtivo privilegiado na escolha dos alimentos. Há grandes diferenças nas cadeias de produção de alimentos que utilizam recursos e insumos de formas distintas, mais ou menos sustentáveis. Dentre os alimentos com maior impacto ambiental estão as carnes, subprodutos à base de carne, e os laticínios, visto que exigem mais recursos naturais e causam maiores emissões de poluentes quando comparados a alternativas à base de vegetais.

Vale ressaltar que as cadeias produtivas de rações para aves exercem impacto no meio ambiente, como reportado no estudo de Ramedani et al. (2019), no qual em todas as categorias de impacto analisadas, a ração para aves foi o principal fator responsável pelos impactos ambientais.

Um outro estudo verificou que a produção de ração para aves representou o maior impacto na poluição ambiental no ciclo de vida. $\mathrm{Na}$ alimentação de frangos, as culturas de milho, trigo e soja tiveram o maior efeito negativo no meio ambiente (GHASEMPOUR; AHMADI, 2016).

A contribuição do PNAE no desenvolvimento sustentável merece destaque, por oferecer muitas refeições, com aquisição de gêneros alimentícios em ampla escala. Portanto, apresenta elevado potencial para impactar nas questões ambientais, seja no planejamento do cardápio, no uso dos recursos, no processo de produção das refeições e em ações educativas que podem imprimir novos padrões de consumo na comunidade (TRICHES, 2015).

É importante destacar que a alimentação ou consumo sustentável refere-se às práticas que encorajam o desenvolvimento sustentável, interconectando as preocupações ambientais com as práticas de produção e consumo e suas consequências para as presentes e futuras gerações (TRICHES, 2015).

Neste sentido, evidencia-se a necessidade de mudanças na forma de pensar as cadeias produtivas de refeições e associá-las com a educação alimentar sustentável. As instituições de ensino podem contribuir para o fortalecimento destas ações. Ao produzirem um número elevado de refeições para os seus alunos, com aquisição de gêneros alimentícios em grande escala, que representam elevado potencial de impactar o meio ambiente, tanto no planejamento do cardápio quanto no uso dos recursos e/ou no processo de produção das refeições, elas podem realizar estratégias sustentáveis em suas duas vertentes: produção de refeições sustentáveis e a educação alimentar sustentável.

Oostindjer et al. (2016) destacam a necessidade de uma nova fase de desenvolvimento da alimentação escolar como uma plataforma de aprendizagem integrativa para um comportamento alimentar saudável e sustentável.

A educação alimentar efetiva não deve situar-se apenas em ações de treinamento, pois ela deve extrapolar a educação formal e se inserir no conjunto de práticas que moldam o ambiente no qual os indivíduos estão 
inseridos. Portanto, a educação alimentar sustentável praticada pelas instituições de ensino estaria além do simples repasse de informações, mas também envolvendo situações em que as pessoas coloquem o discurso em prática, questionando e modificando o meio em que vivem (TRICHES, 2015).

Ações em torno do incentivo à elaboração de hortas escolares, compras da agricultura familiar, ações de educação alimentar e nutricional enfatizando a implicação da escolha dos alimentos e seu impacto ao meio ambiente e na saúde do escolar, são exemplos de estratégias que podem ser realizadas pelas unidades escolares.

Compreender que a escolha de cada alimento pode representar diferentes impactos ao meio ambiente é reconhecer a nossa importância na cadeia produtiva. Tal entendimento pode levar ao incentivo da autonomia na escolha e, desta forma, maior adesão a uma alimentação de qualidade e sustentável.

Ademais, estudos com o foco na avaliação do potencial de diferentes ferramentas na análise de cardápios da alimentação escolar podem suscitar políticas que contribuam para a realização e gestão de cardápios sustentáveis. Contudo, não se pode perder do horizonte a diversidade socioeconômica, as desigualdades sociais e, fundamentalmente, garantir cardápios nutricionalmente adequados. Assim, a escolha dos alimentos que irão compor os cardápios da alimentação escolar pode representar uma importante estratégia em favor de práticas mais sustentáveis.

No presente estudo utilizou-se para os cálculos realizados os per capitas planejados aos alunos no cardápio escolar, porém vale lembrar que em diversas situações há repetições de refeições. Sendo assim, uma limitação do estudo situa-se na implicação da não pesagem das preparações feitas pelos manipuladores de alimentos. Esta pode variar de unidade escolar e, desta forma, o resultado das pegadas encontradas é uma média das refeições oferecidas e dos impactos ambientais de tais cardápios.

\section{Conclusões}

A análise dos cardápios, por meio de indicadores de sustentabilidade ambiental e composição nutricional, apontou que o tipo de alimento incluído nestes pode impactar no meio ambiente mantendo a qualidade nutricional da alimentação escolar. Apesar dos cardápios compostos por proteína animal apontarem maior impacto ao meio ambiente quando comparado ao cardápio do dia da AC, o tipo de proteína animal escolhida deve ser considerado no planejamento dos cardápios.

O Programa Nacional de Alimentação Escolar, hoje considerado uma das políticas públicas mais bem-sucedidas no campo da segurança alimentar e nutricional, possui o nutricionista como responsável técnico, que dentre outras funções define a composição dos cardápios com base em diversos parâmetros, tais como as diretrizes alimentares, necessidades nutricionais dos escolares,

revista brasileira educação ambiental 
perfil de produção local de alimentos, infraestrutura das unidades de alimentação e nutrição e recursos disponíveis.

Contudo, de modo geral a inclusão da sustentabilidade socioambiental como parâmetro para a escolha dos alimentos que irão compor os cardápios escolares ainda parece pouco explorada. Estudos como esse pode oportunizar esse debate no âmbito da escola pública e da gestão de políticas públicas de alimentação e nutrição com vistas a produzir resultados concretos nos indicadores ambientais. Não obstante, deve-se considerar os diferentes contextos socioeconômicos a fim de salvaguardar o direito de todos a uma alimentação adequada e saudável para o pleno crescimento e desenvolvimento do escolar.

\section{Agradecimentos}

O presente trabalho foi realizado com apoio da Coordenação de Aperfeiçoamento de Pessoal de Nível Superior - Brasil (CAPES) - Código de Financiamento 001.

\section{Referências}

BRASIL. Ministério da Educação. Fundo Nacional de Desenvolvimento da Educação Conselho Deliberativo. Resolução no 26 de 17 de junho de 2013. Disponível em <http://www.fnde.gov.br/acesso-ainformacao/institucional/legislacao/item/4620-resolu\%C3\%A7\%C3\%A3o-cdfnde-n\%C2\%BA-26,-de-17-de-junho-de-2013>. Acesso em: 25 de outubro de 2020.

BRASIL. Ministério da Educação/Fundo Nacional de Desenvolvimento da Educação. Resolução no 6, de 8 de maio de 2020. Dispõe sobre 0 atendimento da alimentação escolar aos alunos da educação básica no âmbito do Programa Nacional de Alimentação Escolar - PNAE. Diário Oficial da União, Brasília, ed.89, seção 1, p.38-44, mai. 2020. Disponível em $<$ https://www.in.gov.br/en/web/dou/-/resolucao-n-6-de-8-de-maio-de-2020256309972>. Acesso em: 25 de outubro de 2020.

BRASIL. Ministério da Educação/Fundo Nacional de Desenvolvimento da Educação. Lei no 11.947, de 16 de junho de 2009. Dispõe sobre o atendimento da alimentação escolar e do Programa Dinheiro Direto na Escola aos alunos da educação básica. Diário Oficial da União, Brasília, DF, 17 jun. 2009a. Disponível em <http://www.planalto.gov.br/ccivil 03/ Ato20072010/2009/Lei/L11947.htm>. Acesso em: 21 de agosto de 2018.

BRASIL. Ministério da Educação/Fundo Nacional de Desenvolvimento da Educação. Índice de Qualidade da Coordenação de Segurança Alimentar e Nutricional - $\quad$ IQCOSAN. 2018. Disponível em $<$ http://www.fnde.gov.br/index.php/acessibilidade/item/12142-iq-cosan>. Acesso em: 23 de setembro de 2020. 
BRASIL. Ministério da Saúde. Secretaria de Atenção à Saúde. Departamento de Atenção Básica. Guia alimentar para a população brasileira. 2014. Disponível em $<$ https://bvsms.saude.gov.br/bvs/publicacoes/guia alimentar populacao brasil eira 2ed.pdf $>$. Acesso em: 12 de novembro de 2020.

CHEN, C.; CHAUDHARY, A.; MATHYS, A. Dietary Change Scenarios and Implications for Environmental, Nutrition, Human Health and Economic Dimensions of Food Sustainability. Nutrients. v. 16, n. 11 (4), p. 856, 2019.

EUSTACHIO, C.P.; PATTERSON, E.; LINDROOS, A.; PARLESAK, A.; ELINDER, L.S. Sustainable and acceptable school meals through optimization analysis: an intervention study. Nutrition Journal, v.19, n. 61, p. 1-15, Junho/2020.

FOOD AND AGRICULTURE ORGANIZATION OF THE UNITED NATIONS. Definition of sustainable diets. Paper presented at: International Scientific Symposium: Biodiversity and Sustainable Diets United Against Hunger. 2010, Rome, Italy. Disponível em <http://www.fao.org/ag/humannutrition/285070e8d8dc364ee46865d5841c48976e9980.pdf>. Acesso em: 30 de outubro de 2020.

GARZILLO, J.M.F. et al. Pegadas dos alimentos e das preparações culinárias consumidos no Brasil. 2019, São Paulo: Faculdade de Saúde Pública da USP. Disponível em http://colecoes.sibi.usp.br/fsp/items/show/3592 >. Acesso em: 21 de novembro de 2019.

GHASEMPOUR, A.; AHMADI, E. Assessment of environment impacts of egg production chain using life cycle assessment. Journal of Environmental Management, v. 183, n. 3, p. 980-987, Dezembro/2016.

HIGH LEVEL PANEL OF EXPERTS. Nutrition and food systems. A report by the High Level Panel of Experts on Food Security and Nutrition of the Committee on World Food Security. 2017, Roma. Disponível em $<$ http://www.fao.org/3/a-i7846e.pdf>. Acesso em: 09 de junho de 2020.

INSTITUTO NACIONAL DE ESTUDOS E PESQUISAS EDUCACIONAIS ANÍSIO TEIXEIRA. Resultados Finais do Censo Escolar 2019. Disponível em <http://portal.inep.gov.br/web/guest/resultados-e-resumos $>$. Acesso em: 30 de outubro de 2020.

LIED, E.B.; MAGALHÃES, A.P.; SOARES, D.F.; TREVISAN, A.P.; MOREJON, C.F.M. Sustentabilidade Ecológica pelo cálculo da Pegada Ecológica. Ambiência. Paraná, v. 15, n. 1, p. 240-256, Janeiro/2019.

MARTINELLI, S. S; CAVALLI, S.B. Alimentação saudável e sustentável: uma revisão narrativa sobre desafios e perspectivas. Ciência \& Saúde Coletiva. Rio de Janeiro, v. 24, n. 11, p. 4251-4262, Novembro/2019 .

NÚCLEO DE ESTUDOS E PESQUISAS EM ALIMENTAÇÃO NEPA/UNICAMP. Tabela brasileira de composição de alimentos - TACO $4^{\text {a }}$ 
edição revisada e ampliada. 2011, Campinas. Disponível em $<$ https://www.cfn.org.br/wp-content/uploads/2017/03/taco 4 edicao ampliada e revisada.pdf $>$. Acesso em:10 de janeiro de 2020.

OOSTINDJER, M.; ASCHEMANN-WITZEL, J.; WANG, Q.; SKULAND, S.E,; EGELANDSDAL, B.; AMDAM, G.V.; SCHJØLL, A.; PACHUCKI, M.C.; ROZIN, P.; STEIN, J.; LENGARD ALMLI, V.; VAN KLEEF, E. Are school meals a viable and sustainable tool to improve the healthiness and sustainability of children's diet and food consumption? A cross-national comparative perspective. Critical Reviews in Food Science and Nutrition, v. 12, n. 57(18), p. 3942-3958, Dezembro/2017.

ORGANIZAÇÃO DAS NAÇÕES UNIDAS. Transformando Nosso Mundo: A Agenda 2030 para o Desenvolvimento Sustentável. 2015, Brasília. Disponível em <http://www.itamaraty.gov.br/images/ed desenvsust/ Agenda2030-completo-site.pdf >. Acesso em: 09 de junho de 2020.

PINHEIRO, A.B.V.; LACERDA, E.M.A.; BENZECRY, E.H.; GOMES, M.C.S.; COSTA, V.M. Tabela para Avaliação de Consumo Alimentar em Medidas Caseiras. São Paulo: Ed. Atheneu, 131p. 2008.

RAMEDANI, Z.; ALIMOHAMMADIAN, L.; KHEIALIPOUR, K.; DELPISHEH, P.; ABBASI, Z. Comparing energy state and environmental impacts in ostrich and chicken production systems. Environmental science and pollution research international, v. 26, n. 27, p. 28284-28293, Setembro/2019.

RANGANATHAN, J.; VENNARD, D.; WAITE, R.; DUMAS, P.; LIPINSKI, B.; SEARCHINGER, T. et al. Shifting Diets for a Sustainable Food Future. Working Paper, Installment 11 of Creating a Sustainable Food Future. 2016, Washington, DC: World Resources Institute. Disponível em $<$ https://sustainability.ucsf.edu/upload/livinggreen/files/Shifting Diets for a Sus tainable Food Future.pdf >. Acesso em: 09 de junho de 2020.

ROSE, D.; HELLER, M.C.; ROBERTO, C.A. Position of the Society for Nutrition Education and Behavior: The Importance of Including Environmental Sustainability in Dietary Guidance. Journal of Nutrition Education and Behavior, v. 51, n. 1: 3-15, Janeiro/2019.

ROSI, A.; MENA, P.; PELLEGRINI, N.; TURRONI, S.; NEVIANI, E.; et al. Environmental impact of omnivorous, ovo-lacto-vegetarian, and vegan diet. Sci Rep, v. 7, n. 6105: 1-9, Julho/2017.

TRICHES, R.M. Promoção do consumo alimentar sustentável no contexto da alimentação escolar. Trabalho, Educação e Saúde. Rio de Janeiro, v. 13, n. 3: 757-771, Dezembro/2015. 